\title{
Do rye product structure, product perceptions and oral processing modulate satiety?
}

\section{Pentikäinen, Saara}

2017-04-27

Pentikäinen , S , Sozer , N, Närväinen , J , Sipila , K, Alam , S A , Heiniö , R-L , Paananen , J , Poutanen , K \& Kolehmainen, M 2017 , ' Do rye product structure, product perceptions and oral processing modulate satiety? ' , Food Quality and Preference , vol. 16 , pp. 178-187 . https://doi.org/10.1016/j.foodqual.2017.04.011

http://hdl.handle.net/10138/206656

https://doi.org/10.1016/j.foodqual.2017.04.011

acceptedVersion

Downloaded from Helda, University of Helsinki institutional repository.

This is an electronic reprint of the original article.

This reprint may differ from the original in pagination and typographic detail.

Please cite the original version. 


\section{Accepted Manuscript}

Do rye product structure, product perceptions and oral processing modulate satiety?

Saara Pentikäinen, Nesli Sozer, Johanna Närväinen, Kirsi Sipilä, Syed Ariful Alam, Raija-Liisa Heiniö, Jussi Paananen, Kaisa Poutanen, Marjukka

Kolehmainen

PII:

S0950-3293(17)30095-2

DOI: http://dx.doi.org/10.1016/j.foodqual.2017.04.011

Reference: FQAP 3312

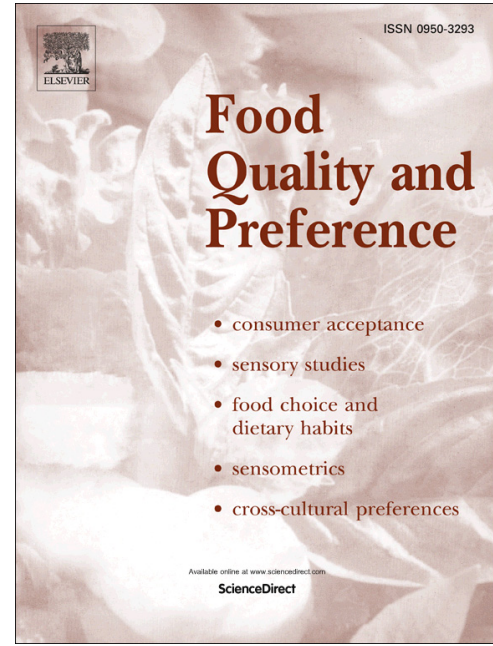

To appear in:

Food Quality and Preference

Received Date: $\quad 20$ December 2016

Revised Date: $\quad 23$ March 2017

Accepted Date: $\quad 26$ April 2017

Please cite this article as: Pentikäinen, S., Sozer, N., Närväinen, J., Sipilä, K., Ariful Alam, S., Heiniö, R-L., Paananen, J., Poutanen, K., Kolehmainen, M., Do rye product structure, product perceptions and oral processing modulate satiety?, Food Quality and Preference (2017), doi: http://dx.doi.org/10.1016/j.foodqual.2017.04.011

This is a PDF file of an unedited manuscript that has been accepted for publication. As a service to our customers we are providing this early version of the manuscript. The manuscript will undergo copyediting, typesetting, and review of the resulting proof before it is published in its final form. Please note that during the production process errors may be discovered which could affect the content, and all legal disclaimers that apply to the journal pertain. 


\section{Do rye product structure, product perceptions and oral processing modulate satiety?}

Saara Pentikäinen ${ }^{a^{*}}$, Nesli Sozer ${ }^{\mathrm{a}}$, Johanna Närväinen ${ }^{\mathrm{a}}$, Kirsi Sipiläb,c,d,e, Syed Ariful Alamª ${ }^{\mathrm{a}}$, RaijaLiisa Heiniö $^{\mathrm{a}}$, Jussi Paananen ${ }^{\mathrm{f}}$, Kaisa Poutanen $^{\mathrm{a}}$, Marjukka Kolehmainen ${ }^{\mathrm{a}, \mathrm{g}, \mathrm{h}}$

${ }^{\text {a }}$ VTT Technical Research Centre of Finland Ltd, P.O. Box 1000, FI-02044 VTT, Finland (email: saara.pentikainen@vtt.fi, nesli.sozer@vtt.fi, johanna.narvainen@vtt.fi, ariful.alam@vtt.fi, raija-liisa.heinio@vtt.fi, kaisa.poutanen@vtt.fi, marjukka.kolehmainen@vtt.fi)

${ }^{\mathrm{b}}$ Institute of Dentistry, University of Eastern Finland, P.O.Box 1627, FI-70211 Kuopio, Finland

${ }^{\mathrm{c}}$ Oral and Maxillofacial Department, Kuopio University Hospital, Kuopio, Finland

${ }^{\mathrm{d}}$ Research Unit of Oral Health Sciences, Faculty of Medicine, University of Oulu, Oulu, Finland

e Oral and Maxillofacial Department, Medical Research Center Oulu, Oulu University Hospital, Oulu, Finland

(email: kirsi.sipila@uef.fi)

${ }^{\mathrm{f}}$ Bioinformatics Center/Institute of Biomedicine, University of Eastern Finland, P.O. Box 1627, FI-70211 Kuopio, Finland

(email: jussi.paananen@uef.fi)

${ }^{\mathrm{g}}$ Department of Clinical Nutrition, Institute of Public Health and Clinical Nutrition, University of Eastern Finland, P.O. Box 1627, FI-70211 Kuopio, Finland

${ }^{\mathrm{h}}$ Kuopio University Hospital, Kuopio, Finland

(email: marjukka.kolehmainen@uef.fi)

*Corresponding author: Saara Pentikäinen (mailing address: VTT Tietotie 2, P.O. Box 100002044

VTT, email: saara.pentikainen@vtt.fi, tel.: +358 40170 8922) 


\section{Abstract}

Food structure and cephalic phase factors are hypothesized to contribute to postprandial satiety in addition to established food properties such as energy content, energy density, and macronutrient and fibre composition of a preload. This study aimed to evaluate if the structure of rye products has an impact on subjective feelings of satiety, and whether cephalic phase factors including oral processing, satiety expectations and perceived pleasantness modulate the interaction. Four wholegrain rye based samples (extruded flakes and puffs, bread and smoothie) were studied in terms of texture characteristics, in vivo oral processing, and expected satiety $(n=26)$ and satiety as well as perceived pleasantness $(n=16)$ (ClinicalTrials.gov number: NCT02554162). The vast textural differences between products were reflected in mastication process, perceived pleasantness and satiety expectations. Extruded products required the most intensive mastication. Rye puffs and rye bread which were characterized by a solid and porous structure, and showed better satiety effect in the early postprandial phase compared to other products. Mastication effort interacted with satiety response. However, the products requiring the highest mastication effort were not the most satiating ones. It seems that there are some food structure related mechanisms that influence both mastication process and postprandial satiety, the mastication process itself not being the mediating factor. Higher palatability seems to weaken postprandial satiety response.

\section{Keywords:}

satiety; cross-over; postprandial; food structure; texture; oral processing 
$1 \quad 1$ Introduction

2 The feeling of satiety has been proposed to support weight management through various routes such

3 as greater food reward, reduced hunger and better control of energy intake (Hetherington et al.,

4 2013). For instance, the amount and type of dietary fibre in food, macronutrient composition and

5 energy density of food contribute to the modulation of satiety. In addition, cognitive and sensory

6 signals generated before and during eating (cephalic phase) are proposed to influence satiation

7 (intra-meal satiety) and satiety (inter-meal satiety) (Blundell et al., 2010). Cephalic phase responses

8 such as stimulation of hormone and enzyme secretion are hypothesized to enhance nutrient

9 processing and thus to enhance also satiety response (Smeets, Erkner, \& De Graaf, 2010).

10 Signals that are generated already during oral processing are needed for optimal appetite regulation,

11 in addition to signals originating from later phases of digestion (Smeets et al., 2010). The

12 importance of oral phase for appetite regulation has been well established in studies where appetite

13 suppression has been incomplete after infusing food directly to stomach. Hogenkamp and Schiöth

14 recently reviewed studies on oral processing of food, satiation and satiety, and concluded that

15 viscosity of food had consistent impact on ad libitum food intake (satiation) and that orosensory

16 exposure was the mediating factor between viscosity and satiation (Hogenkamp \& Schiöth, 2013).

17 Later, Bolhuis et al. showed that hard foods which were eaten in smaller bites than soft foods and

18 processed longer in mouth, reduced the energy intake during the meal, and that the effect was

19 sustained over the following meal (Bolhuis et al., 2014). They concluded that the differences in oral

processing might mediate this effect. Mastication process has also shown to suppress gastric

21 emptying rate (Ohmure et al., 2012).

22 The effects of preload texture and resulting oral processing on postprandial satiety have been

23 investigated in several studies. Energy intake at next meal context is adjusted only partly after a 
24 liquid preload while it is fully adjusted after semi-solid or solid preload (Almiron-Roig et al., 2013).

25 This leads to lower overall caloric intake (preload and ad libitum meal) after semi-solid or solid preloads compared to liquid preload. This indicates that food texture, at least when liquids are compared to solids or semi-solids, plays a role not only in satiation but also in satiety response. However, the results concerning food textures other than liquids, resulting in varying orosensory exposure, are somewhat inconsistent (Hogenkamp \& Schiöth, 2013). Satiety effect of foods with either solid or heterogeneous texture, assumed to induce high orosensory exposure, or corresponding comminuted texture, assumed to induce low orosensory exposure, have been compared by various groups: Mattes et al. found that there were no differences in satiety responses between solid and semi-solid foods (apple vs. apple soup, peanut vs. peanut soup or chicken vs. chicken soup) (Mattes, 2005) whereas later (Flood-Obbagy \& Rolls, 2009) a whole apple was concluded to induce satiety more than apple sauce and the whole apple also reduced energy intake in the following meal. Martens et al. showed that solid food (steamed chicken breast) resulted in enhanced satiety response compared to liquefied food (blended steamed chicken breast) (Martens, Lemmens, Born, \& Westerterp-Plantenga, 2011) whereas Flood and Rolls showed that there was no difference in satiety response whether soup was offered as separate broth and vegetables versus pureed soup (Flood \& Rolls, 2007). Also heterogeneous and homogeneous yoghurts resulted in similar satiety response (Tsuchiya, Almiron-Roig, Lluch, Guyonnet, \& Drewnowski, 2006). To summarize, the evidence regarding the importance of food texture and oral processing on satiety is inconsistent. Most of the studies do not report oral processing precisely. The influence of oral processing on appetite has been studied also in experimental settings where the same foods have been eaten varying the number of chews or mastication time as instructed by the researchers. The results of such studies have been inconsistent: some reports indicate that increasing number of chews or mastication time improves satiety but others show no connection (Hogenkamp \& Schiöth, 2013). 
49 Sensory characteristics of foods such as chewiness and saltiness (Forde, van Kuijk, Thaler, de

50 Graaf, \& Martin, 2013), anticipated creaminess (McCrickerd, Lensing, \& Yeomans, 2015) and

51 thickness and creaminess (Yeomans \& Chambers, 2011) have been found to influence on expected satiety. Even expectations about the satiating capacity of foods evoked by visual and other sensory

53 perceptible cues have shown to influence the actual satiety response: In the study of Brunstrom et al 54 participants were shown either a large or a small portion of fruits prior to consuming an equal size 55 fruit smoothie (Brunstrom, Brown, Hinton, Rogers, \& Fay, 2011). The participants who saw the 56 larger fruit portion reported higher expectations of satiety and in fact also experienced enhanced 57 satiety for three hours. Liking of food has also been repeatedly shown to influence appetite reflected as an increased intake as palatability increases (Sørensen, Møller, Flint, Martens, \& Raben, 2003). However, results concerning the importance of palatability on postprandial satiety remain

60 inconclusive. To summarize, cephalic phase factors including oral processing, perception about 61 pleasantness of food as well as expectations about its satiating capacity may all work together to 62 modulate the satiety response.

63 The current study aimed to evaluate if the structure of rye products influences subjective feelings of 64 satiety, and if cephalic phase factors including oral processing, satiety expectations and evaluated 65 pleasantness are mediating the interaction. The use of rye products as model foods allowed the 66 comparison of extreme food structures with only minor differences in chemical composition. 
68

69

70

71

72

74

75

76

77

78

79

80

81

82

83

84

85

\section{Materials and Methods}

\subsection{Products and their nutrient contents}

The test foods were wholegrain rye products representing varying structures; wholegrain sourdough rye bread, extruded wholegrain rye flakes, extruded wholegrain rye puffs and wholegrain rye smoothie (Table 1 and Figure 1). Wheat bread was included as a control product. Wholegrain sourdough rye bread (wholegrain rye flour, water, salt) and refined wheat bread (wheat flour, water, yeast, sugar, rapeseed oil, salt) were commercially available products by local bakery (Emil Halme). Wholegrain rye puffs and flakes were prepared at VTT using whole grain rye flour (Oy Karl Fazer AB/Fazer Mills and Mixes, Lahti, Finland) and salt (0.8\%) as ingredients. A twin screw extruder (APV MPF 19/25, Baker Perkins Group Ltd, Peterborough, UK) was used to produce the extrudates with a constant feed rate of $60 \mathrm{~g} / \mathrm{min}$ and temperature profile of $80-95-110-120{ }^{\circ} \mathrm{C}$ (section 1 to die exit) with the screw speed of 350 and $250 \mathrm{rpm}$ for puffs and flakes, respectively. Water was pumped into the extruder barrel in order to obtain desired moisture contents in the extrudates. Extruded products were collected continuously from the exit die (diameter $3 \mathrm{~mm}$ ) and dried immediately in an oven at $100{ }^{\circ} \mathrm{C}, 30 \mathrm{~min}$ for puffs and $90 \mathrm{~min}$ for flakes. Wholegrain rye smoothie was prepared mixing grinded wholegrain rye flakes with blackcurrant juice and letting the mixture stand for 15 minutes resulting in a thick smoothie-like heterogeneous texture. Blackcurrant juice was a commercial product (Marli). 


\subsubsection{Instrumental texture}

Texture profile analysis was used to extract the primary and secondary mechanical characteristics of breads by using a texture analyser (TA-XT plus Texture Analyser, Stable Micro System, Godalming, Surrey, UK) with a 25-mm diameter cylinder probe (P/25L Lap Perspex), 30-kg load cell, $60 \%$ strain on 25-mm thick cylindrical pieces of breads which were cut by the help of a mould. Upper crust was included in the pieces. The acquisition rate was 200 points/s and the test speed was $1.7 \mathrm{~mm} / \mathrm{s}$. TPA software (Exponent v.6, Stable Micro System, Godalming, Surrey, UK) was used to extract force-deformation curve. Hardness, cohesiveness, chewiness, and adhesiveness were calculated based on force-deformation curve.

Textural properties of extruded puffs and flakes were analyzed by the uniaxial compression test using a texture analyser (Texture Analyser TA-HDi, HD3071, Stable Micro Systems, United Kingdom) equipped with a $250 \mathrm{~kg}$ load cell and a cylindrical $36 \mathrm{~mm}$ aluminium probe using a protocol used by Alam et al. (Alam et al., 2014). Snack samples were prepared by cutting the extruded ribbons to $10 \mathrm{~mm}$ height and flakes were analysed as is. The samples (50 replicates for each samples) were deformed at $70 \%$ strain with a test speed of $1 \mathrm{~mm} / \mathrm{s}$ and the acquisition rate 200 points/s. Texture Exponent software v.5.1.2.0 (Stable Micro Systems, UK) was used to obtain values of hardness $\left(\mathrm{F}_{\max }\right)$, crispiness work $\left(\mathrm{C}_{\mathrm{w}}\right)$ and crispiness index $\left(\mathrm{C}_{\mathrm{i}}\right)$. High crispiness is accompanied by a high $\mathrm{C}_{\mathrm{i}}$ and low $\mathrm{C}_{\mathrm{w}}$ value, whereas low crispiness corresponds to a low $\mathrm{C}_{\mathrm{i}}$ and high $\mathrm{C}_{\mathrm{w}}$ value. The analysis was performed using the algorithms described by Alam et al. (Alam et al., 2014).

\subsubsection{Perceived characteristics}

All assessors of VTT's internal trained sensory panel $(n=12)$ have passed the basic taste test, the odour test and the colour vision test and trained for sensory profiling. The trained sensory panel was 
109 first familiarized with the sensory assessment of diverse cereal samples. The method in sensory

110 profiling was descriptive analysis (Lawless \& Heymann, 2010). The vocabulary of the sensory

111 attributes was developed by describing the differences between the samples. The assessors

112 familiarized themselves with the products, discussed and defined the key attributes differentiating

113 the products in a training session aiming to produce the descriptors for the sensory profile. The

114 selected attributes included colour darkness, rye flavour intensity, flavour intensity, visual porosity,

115 hardness, crispiness, crunchiness, crumbliness, moisture, adhesion to teeth and work needed for

116 mastication. In sensory profiling the latter was evaluated according to the instructions: "Masticate

117 the sample using your back teeth until the sample is ready to be swallowed. After that, please

118 evaluate how much work was needed for mastication". Actual reference samples were used to

119 define the extremes for most of the attributes, and all descriptors were also verbally anchored. All

120 sensory intensities were evaluated using $10 \mathrm{~cm}$ scale anchored from "not at all" to "extremely". All

121 samples were evaluated by sensory profiling in duplicate sessions in two consecutive days by all the

122 panellists. The samples were blind-coded by 3-digit numbers, and the presentation order of the

123 samples was randomized within each test day. Water was served to the assessors for cleaning the

124 palate between the different samples. The scores were recorded and collected using computerized

125 software (Compusense Five, Ver 5.4.15, CSA, Computerized Sensory Analysis System,

126 Compusense Inc., Guelph, ON, Canada).

1272.2 Participants

128 Participants $(n=26)$ were recruited through public advertisements and email advertisements in

129 Otaniemi campus area nearby the study location. The eligibility of the volunteers was checked

130 beforehand through screening questionnaire. The criteria were: female gender, age 20-40 years,

131 BMI between 18.5 and $27 \mathrm{~kg} / \mathrm{m}^{2}$, stable body weight ( $\pm 4 \mathrm{~kg}$ during the previous year) and a habit

132 of eating breakfast. Smokers, pregnant or lactating women, persons with missing teeth (except $3^{\text {rd }}$ 
133 molars) or with diagnosed acute temporomandibular disorders (TMD) (self-reported) and persons

134 with dietary restrictions possibly affecting the study participation (celiac disease, allergies or

135 aversions to cereal foods or high carbohydrate foods) or abnormal eating behaviour according

136 Eating Disorder Diagnostic Scale (EDDS) were excluded. Young healthy females were recruited to

137 diminish the variation in mastication pattern. The interested volunteers fulfilling the inclusion

138 criteria were invited to an info visit. Volunteers deciding to participate signed an informed consent

139 form. The whole study population $(n=26)$ participated in mastication trial and a subgroup of 20

140 participants started the satiety trial. The both trials were conducted during October-December 2015.

141 Sixteen of these participants completed all the study visits and four discontinued due to personal

142 reasons. Characteristics of the participants are described in Table 2. Two participants were older

143 than 40 years (48 and 50 years). However, since they fulfilled all the other inclusion criteria they

144 were included in the study, as the number of recruited participants was not as high as desired. The

145 participants were given one movie ticket per study visit to compensate their time and effort. The

146 study protocol was approved by the Coordinating Research Ethics Committee of the Helsinki and

147 Uusimaa Hospital District. The study was conducted according to the ethical principles of good

148 research and clinical practice described in the declaration of Helsinki. The trial was registered in

149 ClinicalTrials.gov (NCT02554162).

$150 \quad 2.3 \quad$ Mastication trial

$151 \quad 2.3 .1 \quad$ Procedure

152 The mastication trial followed a cross-over, single-blind design, in which all participants masticated

153 the five samples in random order. The participants were instructed to eat a breakfast $1-1.5$ hours

154 before the visit scheduled between $8-11$ a.m. The study procedure was first practiced with a test

155 sample and the coded food samples were served to the participant in random order, each sample in

156 three portions. Portion sizes represented a mouthful of food: $2 \times 2 \times 2 \mathrm{~cm}$-size cube of bread 
157 (including crust in one side) (approx. $7.7 \mathrm{~g}$ ), one table spoon of flakes $(3.5 \mathrm{~g})$, two $2 \mathrm{~cm}$ pieces of

158 puffs $(1 \mathrm{~g})$ and one table spoon of rye smoothie $(16.8 \mathrm{~g})$. The participants were instructed to

159 masticate each portion of sample until subjective swallowing point and then expectorate the bolus.

160 The three portions of each sample were masticated in a row and there was break between different

161 samples during which mouth was rinsed with water and the expected satiety rating for each sample

162 was evaluated. As a final sample, the participant was served three portions (=piece) of chewing gum

163 and she was asked to chew each piece for 20 seconds. Electromyography measures electrical

164 activity of the facial muscles and even if the measured voltage is linearly relative to the force

165 generated by the muscle, the calibration varies between different subjects and even the four muscles

166 monitored. Thus, to get an indication of the relative force needed to masticate each of the samples

167 individual data on oral processing of chewing gum was used as a reference for force parameters.

168 The mastication trial visits were video recorded to support data analysis.

169 2.3.2 Electromyography (EMG) measurements

170 The mastication process was characterised by measuring the electrical activity of masticatory

171 muscles by EMG equipment (Mega Electronics, Kuopio, Finland) using disposable dermal

$172 \mathrm{Ag} / \mathrm{AgCl}$ electrodes. The skin was cleaned with $70 \%$ ethanol alcohol, masseter and temporal

173 muscles were identified by touch when the participant gritted her teeth and bipolar electrodes were

174 placed on them on both sides of the face. A reference electrode was placed on cervical vertebra.

175 EMG activity was measured continuously throughout the whole mastication trial. The data block

176 starts and ends for each chewing period were both marked in the EMG acquisition system (Figure

177 2A) and recorded manually. From the EMG time series, the onset, duration and amplitude of each

178 chew were extracted by applying chemometric techniques for the elimination of high frequencies

179 and background fluctuations as in the study of Pentikäinen et al. (Pentikäinen, Sozer, et al., 2014)

180 (Figure 2B). Chewing force and work parameters were normalized to chewing process of chewing 
181

182

183

184

185

186

187

188

190

191

192

194

195

196

198

199

gum. As a result of data processing and analyses, the duration of oral processing, duration of EMG activity, duty cycle (duration of EMG activity/duration of chewing), number of chews, relative chewing force (highest EMG amplitude for the product normalized to highest EMG amplitude for chewing gum) and relative work (time of EMG activity x relative chewing force) were calculated for each test food. All analysis of EMG data was done using Matlab® (The MathWorks Inc., Natick, MA, USA). The values for duration of EMG activity, duration of oral processing, number of chews and relative work were extrapolated to represent the amount served later in the satiety trial. The coefficients were determined by dividing the weight of the whole portion served in the satiety trial by the weight of one mouthful of food used in mastication trial. Coefficients for rye bread, rye smoothie, rye puffs, rye flakes and wheat bread were $12.4 ; 32.8: 58 ; 16.9$ and 19.2 , respectively.

\subsubsection{Expected satiety}

The participant was asked to evaluate the satiating capacity of the samples before and after mastication of each study product. This part was included in order to find out whether food structure evaluated based on visual cue (picture) or with both visual and sensory cues (mastication) influences anticipated satiety effect. The evaluation was based on a photograph showing a portion including a fixed amount of sample and a glass of juice. The portions in photographs were the same size as the portions that were later used in the satiety trial. The questions, as translated from Finnish were: (before mastication) "Imagine that you would eat the whole portion of food shown in the photograph. Evaluate how satiated you would feel after one hour." and (after mastication) "You have just masticated the product shown in the photograph. Imagine that you would eat the whole portion of food shown in the photograph. Evaluate how satiated you would feel after one hour". The evaluation was done on $10 \mathrm{~cm}$ visual analogue scale (VAS) anchored with $0=$ not at all satiated, $10=$ extremely satiated. 


\subsection{Satiety trial}

205

The satiety trial followed a cross-over, single-blind design, in which all participants tested the five study portions in random order, each portion on a separate day. There were at least two washout days between two consecutive study visits. The participants were instructed to follow their usual eating and exercise habits during the day preceding each study visit and to fast at least 10 hours before arriving to the study visit.

The study visits started in the morning between 7 and 9 a.m. The test portion sizes were matched by energy content each portion providing $380 \mathrm{kcal}$ of energy (Table 1). The portions consisted of blackcurrant juice $(5 \mathrm{dl})$ and of either $95 \mathrm{~g}$ of wholegrain (WG) sourdough rye bread, $59 \mathrm{~g}$ of WG rye flakes, $58 \mathrm{~g}$ of WG rye puffs or $75 \mathrm{~g}$ refined wheat bread. WG rye smoothie was prepared by mixing $59 \mathrm{~g}$ of grinded rye flakes in $5 \mathrm{dl}$ blackcurrant juice. The participants were instructed to eat and drink the test products at their own pace but not to spend more than 20 min on eating. Satiety related sensations were evaluated before and right after consuming the test portion and repetitively every 30 min until 210 min after starting point of the consumption using $10 \mathrm{~cm}$ visual analogue scales (VAS) anchored with extremes $(0=$ not at all, $10=$ extremely). The evaluated sensations were hunger, fullness, satiety, desire to eat and prospective food consumption ("How much would you be able to eat right now?"). In addition, pleasantness of the test portion was evaluated after consuming the portion. Average appetite score was afterwards calculated as [desire to eat + hunger $+(10-$ fullness) + prospective food consumption]/4. Computerised data-collecting system (CSA, Computerised Sensory Analysis System, Compusense, Guelph, Canada, Compusense five 5.2) was used to collect the evaluations. 
225

\subsection{Statistical analyses}

IBM SPSS Statistics 22 was used to analyse the data.

Oneway ANOVA was used to study the sensory differences of study products. Pair-wise comparison was conducted by using Tukey's test. Repeated measures ANOVA was used to study the differences in satiety expectations and pleasantness evaluations. Friedman's non-parametric test for related samples was used to compare the parameters describing mastication process. P-value $<0.05$ was considered as statistically significant.

Regarding the satiety evaluations, baseline value of each visual analogue scale parameter was subtracted from the values of subsequent time points to take into account the possible effect of baseline differences on the analysis. Linear mixed-effects models were used to compare the effects of the test portions on the profiles of postprandial satiety responses. The used models included participant as a random factor, and product, time, and product * time interaction as fixed factors.

When a significant main effect of a product or product * time interaction was observed, post hoc analyses were performed using the Sidak correction for multiple comparisons in order to identify the statistically significant differences between the test portions. The contribution of cephalic phase factors was evaluated by adding parameters of oral processing, evaluated pleasantness and satiety expectations to the model as fixed factors one at a time and Schwarz's Bayesian Criterion (BIC) was then used to compare goodness of fit between the models. The smaller the BIC value is the better the model fit is. 
3 Results

\subsection{Characteristics of study products}

\subsubsection{Instrumental texture}

Instrumental texture of the solid products was measured using a texture analyser. The extrudates were dry products with hard and fragile texture whereas breads were springy and moist (Table 3). Rye flakes had the hardest texture and wheat bread the least hard. Hardness of rye puffs and rye bread was similar whereas they had otherwise different textural properties rye puffs being crispy and rye bread being springy. Rye bread was less cohesive, more chewy and adhesive than wheat bread. Puffs were crispier than flakes, indicated by higher crispiness index and lower crispiness 253 work.

\subsubsection{Perceived characteristics}

The sensory characteristics of the samples were evaluated by a trained sensory panel. The products varied significantly in all the evaluated sensory attributes $(\mathrm{p}<0.001$ for all) (Figure 3) as was intended. Rye flakes and rye bread were evaluated to require more work for mastication than the other products (rye flakes vs. rye puffs, smoothie and wheat bread $\mathrm{p}<0.001$; rye bread vs. rye puffs and smoothie $\mathrm{p}<0.001$, rye bread vs. wheat bread $\mathrm{p}=0.004)$. Rye puffs adhered to teeth more than the flakes, breads or smoothie ( $\mathrm{p}<0.001$ for all). Rye flakes and puffs were crumblier, crunchier and

261 crispier compared to the other products $(\mathrm{p}<0.001$ for all). Rye flakes were crunchier than rye puffs $262(\mathrm{p}=0.15)$ and rye puffs were crispier than rye flakes $(\mathrm{p}<0.001)$. Rye flakes were harder than the 263 other products $(\mathrm{p}<0.001$ for all) and rye bread was harder than wheat bread $(\mathrm{p}=0.009)$. Rye puffs 264 and both breads were more porous than rye flakes or smoothie $(\mathrm{p}<0.001)$. Both overall flavour and rye flavour were more intense in rye bread than in other products $(\mathrm{p}<0.001$ for all $)$. 


\subsubsection{Expected satiety and evaluated pleasantness}

The participants of the mastication trial $(n=26)$ evaluated the expected satiating capacity of the products before and after masticating them. The evaluation was based on picture representing isocaloric portions of the products. The satiety expectations differed significantly between the products $(\mathrm{p}<0.001$ for both before and after mastication) (Figure $4 \mathrm{~A})$. The portion containing wholegrain sourdough rye bread was evaluated to be more satiating than the other portions both before mastication (rye bread vs. rye flakes, smoothie and wheat bread $\mathrm{p}<0.001$; rye bread vs. rye puffs $\mathrm{p}=0.031)$ and after mastication $(\mathrm{p}<0.001$ for all) whereas wholegrain rye smoothie portion was evaluated as less satiating than the other portions before mastication ( $p<0.001$ for all) and less satiating than rye bread and rye flakes $(p<0.001$ for both) and wheat bread $(p=0.005)$ after mastication. Expected satiety effects of rye bread, rye flakes and rye smoothie were evaluated higher after than before mastication $(\mathrm{p}=0.001, \mathrm{p}<0.001$, and $\mathrm{p}<0.001$, respectively). There were no differences in the evaluations before and after mastication of rye puffs or wheat bread. The participants of the satiety trial $(n=16)$ evaluated the pleasantness of the consumed portions. There were significant differences in the ratings of pleasantness between the portions $(p<0.001)$ (Figure 4B). The rye bread portion was evaluated as more pleasant than the other portions (rye bread vs. smoothie $\mathrm{p}=0.002$; vs. rye puffs $\mathrm{p}<0.001$; vs. wheat bread $\mathrm{p}=0.011$; vs. rye flakes $\mathrm{p}=0.005$ ) and extruded rye puff portion was evaluated less pleasant than rye bread $(\mathrm{p}<0.001)$, wheat bread $(\mathrm{p}=0.001)$ and rye flake portion $(\mathrm{p}=0.006)$.

\subsection{Mastication properties}

Mastication was characterized by monitoring the electrical activity of facial muscles during masticating mouthful of sample. There were significant differences between products in all the measured oral processing attributes: number of chews, total oral processing time, total EMG activity time, duty cycle, relative force and relative work $(\mathrm{p}<0.001$ for all). Table 4 shows the values for the parameters and the results of pairwise comparisons. Total oral processing time, total 
291 EMG activity time and relative work for mouthful of sample were the highest for rye bread and rye

292 flakes and the lowest for puffs and smoothie. The number of chews was the highest for mouthful of

293 rye flakes and the lowest for puffs and smoothie. It should be noted, however, that for smoothie the

294 events detected as chews are mostly other muscle motions than actual chewing.

295 When the measured oral processing attributes were extrapolated to represent the process of chewing

296 the whole portion of the product (as amount served in the satiety trial) there were also statistically

297 significant differences between products in all the attributes $(\mathrm{p}<0.001)$. Total oral processing time,

298 EMG activity time and relative work per portion were the highest for flakes and puffs and the

299 lowest for smoothie. Number of chews per portion was higher for flakes, puffs and wheat bread

300 than for rye bread or rye smoothie.

$301 \quad 3.3 \quad$ Postprandial satiety responses to food portions

302 Portions of the test products were served to subgroup of 16 participants in the satiety trial. Each

303 portion was served in separate day. The mean VAS ratings for hunger, fullness, desire to eat,

304 prospective food consumption, satiety and average appetite score for the 210 min period are

305 presented in Figure 5. Hunger (Figure 5A) was significantly lower and fullness (Figure 5B) higher

306 at $30 \mathrm{~min}$ after consumption of puff portion compared to flake portion $(\mathrm{p}<0.012$ and $\mathrm{p}<0.028$,

307 respectively) whereas there were no statistically significant differences between other portions.

308 Desire to eat (Figure 5C) was significantly higher at 60 min after consumption of flake portion than

309 rye bread portion $(\mathrm{p}<0.038)$ but there were no differences between other portions. Prospective food

310 consumption (Figure 5D) was significantly higher after consuming flakes compared to puffs at 30

$311 \min$ and $60 \min (\mathrm{p}<0.002$ and 0.028 , respectively) and compared to rye bread at $30 \min (\mathrm{p}<0.018)$.

312 However, there were no other differences between products or in other time points. There were no

313 statistically significant differences in satiety ratings (Figure 5E). Average appetite (a parameter 
314 derived from fullness, prospective food consumption, hunger and desire to eat) (Figure 5F) was

315 significantly higher after consuming flakes compared to puffs at $30 \mathrm{~min}$ and $60 \mathrm{~min}(\mathrm{p}<0.011$,

$316 \mathrm{p}<0.045$, respectively) and compared to rye bread at $30 \mathrm{~min}(\mathrm{p}=0.034)$. Between other products no

317 differences were seen.

3183.4 Postprandial average appetite in relation to oral processing, evaluated pleasantness and satiety

$319 \quad$ expectations

320 Mixed model including product and time as fixed factors, subject as a random factor and average

321 appetite as dependent factor was taken as starting point to study the contribution of cephalic phase

322 factors on average appetite (a parameter derived from fullness, prospective food consumption,

323 hunger and desire to eat). BIC value describing the goodness of fit for this model was 2195.

324 Parameters of oral processing (number of chews per portion and relative work); evaluated

325 pleasantness and satiety expectations were then added to the model as fixed factors one at a time to

326 see whether they influenced the goodness of model fit. Adding the number of chews in the model

327 did not improve the fit (BIC value 2165, p-value for product 0.051 ) but adding a parameter for

328 relative work did improve it (BIC value 1911, p-value for product 0.001). Including evaluated

329 pleasantness improved the fit as well (BIC 1965, p-value for product 0.001). The differences

330 between products were abolished when the evaluations about expected satiety before mastication

331 (BIC 1966, p-value 0.109) and after mastication (BIC 1968, p value for product 0.304) were added

332 in the model.

3334 Discussion

334 The results showed that rye product portions matched by energy content but varying in structure

335 required different type of mastication process and influenced on postprandial satiety measures

336 differently in the early postprandial period. Mastication effort, measured as relative mastication 
337

338

work, and perceived pleasantness seem to interact with satiety response. The portion with rye flakes showed the weakest satiety impact, puffs and rye bread showing the strongest impact and rye smoothie intermediate. Rye puffs and rye bread, having the most beneficial influence on satiety, were both characterized by a solid and porous structure with comparable instrumental and sensory hardness. However, there were many characteristics that differentiate these products: rye bread was soft and springy product and rye puffs crispy, with strong adhesion to teeth, probably attributable of the combination of high content of arabinoxylan and big particle surface area in mastication. Rye flakes, resulting in the weakest satiety response, were characterised as hard and crunchy, and having a non-porous structure requiring intensive mastication effort. The differences in satiety responses in this study occurred already in the early postprandial phase (30 min and $60 \mathrm{~min})$ indicating that cephalic and gastric phase factors were behind the differences.

The mastication process was analysed in a mastication trial measuring the process with EMG. The method makes it possible to evaluate not only mastication time or number of chews but also relative chewing force and mastication effort that is needed to disintegrate the sample in the mouth. The results show that the mouthfuls of samples required different mastication patterns, rye bread and flakes needing the highest number of chews and the longest processing time. Since the number of mouthfuls needed to consume a portion of food (with fixed energy amount) varies, the mastication parameters were extrapolated to represent the values for portions served in the satiety trial. The results show that the number of chews, oral processing time and mastication effort were the highest for portions of rye flakes and rye puffs. Thus, the driest products required the most mastication effort among the studied products.

Number of chews and mastication effort (derived as a product of chewing time and force), were used to represent the mastication process in the statistical models to reveal possible contributions to the satiety. These two parameters were chosen because they are reasonably uncorrelated, while e.g. 
number of chews and chewing time are strongly dependent. Mastication effort was found to

362 improve the model while the number of chews did not influence the goodness of the fit. This

363 indicates that mastication effort would be more relevant oral processing factor than the mere 364 number of chews with respect to the appetite response. However, the obtained result does not 365 support the hypothesis that higher mastication effort would be beneficial for satiety response since 366 the flakes requiring the most intense effort actually resulted in the weakest satiety response. We 367 assume that there are structural properties that are reflected in mastication parameters but actually 368 are relevant for other satiety inducing mechanisms in the body. Differences in stomach distention 369 could offer one plausible explanation: rye bread and rye puffs were porous products which most 370 probably were disintegrated into fairly small particles with good hydration capacities compared to 371 the flakes that have hard and dense structure resulting assumedly bigger particles in mastication. 372 The beverage consumed alongside the flakes is probably emptied rapidly from stomach causing less 373 stomach distention which is among factors influencing satiety. The period of the observed 374 differences supports this hypothesis: the differences in the satiety responses were seen during the 375 first hour after consumption. The rheology of the boluses would be interesting to study in vitro to 376 better understand the impact of food structure for stomach digestion phase.

Rye smoothie portion and portion with rye flakes and juice is an interesting pair to compare since these portions include exactly the same ingredients and similarly produced cereal product (extruded 379 flakes), energy content and volume but in different forms. The smoothie was designed to represent 380 the flakes portion without the need for extensive mastication. Despite being structurally very 381 different, both the products possess properties potentially beneficial for satiety: the flakes required more mastication effort which might be a beneficial property for satiety whereas rye smoothie was a 383 soup-like product which is a food type generally considered having good satiating capacity. Some 384 researchers believe that for maximum satiating power, the water should to be incorporated in the 385 food, as opposed to being consumed alongside the food as a beverage (Almiron-Roig et al., 2013). 
Indeed, rye smoothie tended to induce better satiety compared to rye flake portion although the difference was not statistically significant. One possible explanation may be again in hydration: the rye smoothie was let stand for $15 \mathrm{~min}$ before the satiety trial thus resulting in thick texture with hydrated rye flake particles. Dry rye flakes, which are characterised with low porosity and which have been shown to remain in bigger particles than extruded puffs in mastication (Alam et al., 2016), assumedly do not absorb water promptly and the beverage consumed alongside the flakes is probably emptied rapidly from stomach causing less stomach distention than the juice that is incorporated in the food product. Dhingra et al. concluded in their review about dietary fibre in foods that hydration properties are relevant in explaining the physiological effects of fibres and that for example substrate pore volume impacts the hydration capacity (Dhingra, Michael, Rajput, \& Patil, 2012). Also our earlier study showed that beta-glucan which was added in juice resulted in better satiety response than the same ingredient added in biscuits in study setting having the same basic products (Pentikäinen, Karhunen, et al., 2014).

In addition to mastication process other cephalic phase related factors, such as perceived expectations about the satiating capacity of the food as well as perceived pleasantness may influence the actual satiety response. In the current study the study portions, even though matched with energy, were evaluated differently regarding their satiating capacity: rye bread was evaluated as the most powerful satiety-maintaining product whereas the rye smoothie was evaluated to be poorest to suppress appetite. In addition, the evaluations of the satiating capacities were enhanced after oral processing of the food, especially for rye flakes and rye smoothie which apparently were also unfamiliar foods for the participants. It has been shown that expectations about the satiating capacity of food can influence the actual satiety response and that the effect can last up to three hours (Brunstrom et al., 2011). Adding the evaluated satiety expectations into the mixed model abolished the differences between products. Thus, we assume that the expectations about the satiating capacity of the portions influenced the results. 
411 Rye puff portion was evaluated as the least pleasant, rye bread portion as the most pleasant and 412 other portions intermediate. Regarding the previous studies about the possible influence of 413 pleasantness on satiety these clear differences could not be neglected. Addition of pleasantness 414 ratings into statistical model enhanced the model as well as made the between-product differences 415 more statistically significant ( $\mathrm{p}=0.001$ vs. original $\mathrm{p}$-value of 0.044 ). Thus the evaluated 416 pleasantness of the products indeed was influencing the result. Lower pleasantness ratings for rye 417 puffs may have resulted from considerably big volume of the portion resulting from airy structure. 418 Also strong adhesion to teeth might have influenced the poorer pleasantness ratings.

419 Differences in oral processing can be achieved either by instructing participants to masticate food 420 during a fixed time or by applying fixed number of chews or by providing textures that lead to more 421 longer oral processing patterns. The latter approach is preferable when trying to develop products 422 that would naturally help to control food intake and enhance satiety response. The current study was 423 successful in producing varying food structures resulting in different oral processing pattern. They 424 were not only foods as such and with comminuted structure but realistic products with structural differences including ductile and chewy texture (bread), hard and crunchy texture (flakes) and hard,

426 airy, crispy texture (puffs) and a soup-like texture (smoothie).

427 As a drawback the current study's setting is that the familiarity of the products (even though it was 428 not specifically asked) assumedly was different. Rye bread is a staple food in Finland whereas both extruded rye products and rye smoothie are uncommon food items. It has been seen in earlier studies that earlier experiences about foods help to evaluate their satiety effect (Brunstrom, 431 Shakeshaft, \& Scott-Samuel, 2008). Thus, in further study settings it would be good to familiarize 432 the study participants to each study product beforehand to exclude the possible mixing impact of 433 familiarity. Postprandial satiety responses were measured during 210 minutes following the 434 established practices (3-5 hours) (Blundell et al., 2010). However, in the current study or similar 
435 studies where differences in satiety responses are hypothesized to occur mainly due to cephalic

436 phase or stomach phase factors it might be more informative to measure the responses more

437 frequently during a shorter period.

438 To conclude, the vast textural differences between products were reflected in mastication process

439 and also in the satiety response to food portions with similar energy contents. The results did not

440 support the hypothesis that mastication process itself would mediate the interaction between food

441 structure and postprandial satiety but there appears to be other mechanisms possibly related to

442 stomach phase digestion modulating the interaction. Palatability seems to weaken postprandial

443 satiety response.

444 Acknowledgments: We Riitta Pasanen, Leila Kostamo, Tarja Wikström, Eero Mattila, Anna-Liisa

445 Ruskeepää (VTT Technical Research Centre of Finland) for skilful assistance in preparing the

446 samples, analysing nutrient contents and structural properties of the samples as well as assisting in

447 data collection.

448 Funding: This research did not receive any specific grant from funding agencies in the public,

449 commercial, or not-for-profit sectors. 
450

451

452

453

454

455

456

457

458

459

460

461

462

463

464

465

466

467

References

Alam, S. A., Järvinen, J., Kirjoranta, S., Jouppila, K., Poutanen, K., \& Sozer, N. (2014). Influence of Particle Size Reduction on Structural and Mechanical Properties of Extruded Rye Bran. Food and Bioprocess Technology, 7(7), 2121-2133. https://doi.org/10.1007/s11947-013-12252

Alam, S. A., Pentikäinen, S., Närväinen, J., Holopainen-Mantila, U., Poutanen, K., \& Sozer, N. (2016). Effects of structural and mechanical textural properties of brittle cereal foams on mechanisms of oral breakdown. Food Research International, 96, 1-11. https://doi.org/10.1016/j.foodres.2016.11.026

Almiron-Roig, E., Palla, L., Guest, K., Ricchiuti, C., Vint, N., Jebb, S. A., ... Higgins, J. (2013). Factors that determine energy compensation: a systematic review of preload studies. Nutrition Reviews, 71(7), 458-73. https://doi.org/10.1111/nure.12048

Blundell, J., De Graaf, C., Hulshof, T., Jebb, S., Livingstone, B., Lluch, a., ... Westerterp, M. (2010). Appetite control: Methodological aspects of the evaluation of foods. Obesity Reviews, 11(3), 251-270. https://doi.org/10.1111/j.1467-789X.2010.00714.x

Bolhuis, D. P., Forde, C. G., Cheng, Y., Xu, H., Martin, N., \& de Graaf, C. (2014). Slow food: sustained impact of harder foods on the reduction in energy intake over the course of the day. PloS One, 9(4), e93370. https://doi.org/10.1371/journal.pone.0093370

Brunstrom, J. M., Brown, S., Hinton, E. C., Rogers, P. J., \& Fay, S. H. (2011). "Expected satiety" changes hunger and fullness in the inter-meal interval. Appetite, 56(2), 310-315. https://doi.org/10.1016/j.appet.2011.01.002 
471

472

473

474

475

476

477

478

479

480

481

482

483

484

485

486

487

488

489

490

Brunstrom, J. M., Shakeshaft, N. G., \& Scott-Samuel, N. E. (2008). Measuring "expected satiety" in a range of common foods using a method of constant stimuli. Appetite, 51(3), 604-614. https://doi.org/10.1016/j.appet.2008.04.017

Dhingra, D., Michael, M., Rajput, H., \& Patil, R. T. (2012). Dietary fibre in foods: A review. Journal of Food Science and Technology, 49(3), 255-266. https://doi.org/10.1007/s13197-0110365-5

Flood-Obbagy, J. E., \& Rolls, B. J. (2009). The effect of fruit in different forms on energy intake and satiety at a meal. Appetite, 52(2), 416-422. https://doi.org/10.1016/j.appet.2008.12.001

Flood, J. E., \& Rolls, B. J. (2007). Soup preloads in a variety of forms reduce meal energy intake. Appetite, 49(3), 626-634. https://doi.org/10.1016/j.appet.2007.04.002

Forde, C. G., van Kuijk, N., Thaler, T., de Graaf, C., \& Martin, N. (2013). Texture and savoury taste influences on food intake in a realistic hot lunch time meal. Appetite, 60(1), 180-186. https://doi.org/10.1016/j.appet.2012.10.002

Hetherington, M. M., Cunningham, K., Dye, L., Gibson, E. L., Gregersen, N. T., Halford, J. C. G., ... Van Trijp, H. C. M. (2013). Potential benefits of satiety to the consumer: scientific considerations. Nutrition Research Reviews, 26(1), 22-38. https://doi.org/10.1017/S0954422413000012

Hogenkamp, P. S., \& Schiöth, H. B. (2013). Effect of oral processing behaviour on food intake and satiety. Trends in Food Science and Technology, 34(1), 67-75. https://doi.org/10.1016/j.tifs.2013.08.010 
491

492

493

494

495

496

497

498

499

500

501

502

503

504

505

506

507

508

509

510

511

Karlsson, J., Persson, L. O., Sjöström, L., \& Sullivan, M. (2000). Psychometric properties and factor structure of the Three-Factor Eating Questionnaire (TFEQ) in obese men and women. Results from the Swedish Obese Subjects (SOS) study. International Journal of Obesity and Related Metabolic Disorders: Journal of the International Association for the Study of Obesity, 24(12), 1715-1725. https://doi.org/10.1038/sj.ijo.0801442

Lawless, H. T., \& Heymann, H. (2010). Sensory Evaluation of Food. New York, NY: Springer New York. https://doi.org/10.1007/978-1-4419-6488-5

Martens, M. J. I., Lemmens, S. G. T., Born, J. M., \& Westerterp-Plantenga, M. S. (2011). A Solid High-Protein Meal Evokes Stronger Hunger Suppression Than a Liquefied High-Protein Meal. Obesity, 19(3), 522-527. https://doi.org/10.1038/oby.2010.258

Mattes, R. (2005). Soup and satiety. Physiology \& Behavior, 83(5), 739-747. https://doi.org/10.1016/j.physbeh.2004.09.021

McCrickerd, K., Lensing, N., \& Yeomans, M. R. (2015). The impact of food and beverage characteristics on expectations of satiation, satiety and thirst. Food Quality and Preference, 44, 130-138. https://doi.org/10.1016/j.foodqual.2015.04.003

Ohmure, H., Takada, H., Nagayama, K., Sakiyama, T., Tsubouchi, H., \& Miyawaki, S. (2012). Mastication suppresses initial gastric emptying by modulating gastric activity. Journal of Dental Research, 91(3), 293-8. https://doi.org/10.1177/0022034511433847

Pentikäinen, S., Karhunen, L., Flander, L., Katina, K., Meynier, A., Aymard, P., ... Poutanen, K. (2014). Enrichment of biscuits and juice with oat $\beta$-glucan enhances postprandial satiety. Appetite, 75, 150-156. https://doi.org/10.1016/j.appet.2014.01.002 
512 Pentikäinen, S., Sozer, N., Närväinen, J., Ylätalo, S., Teppola, P., Jurvelin, J., ... Poutanen, K. 513 (2014). Effects of wheat and rye bread structure on mastication process and bolus properties. 514 Food Research International, 66, 356-364. https://doi.org/10.1016/j.foodres.2014.09.034

515 Smeets, P. a M., Erkner, A., \& De Graaf, C. (2010). Cephalic phase responses and appetite. 516 Nutrition Reviews, 68(11), 643-655. https://doi.org/10.1111/j.1753-4887.2010.00334.x

517

518

520

Sørensen, L. B., Møller, P., Flint, a, Martens, M., \& Raben, a. (2003). Effect of sensory perception of foods on appetite and food intake: a review of studies on humans. International Journal of Obesity and Related Metabolic Disorders: Journal of the International Association for the Study of Obesity, 27(10), 1152-1166. https://doi.org/10.1038/sj.ijo.0802391

Tsuchiya, A., Almiron-Roig, E., Lluch, A., Guyonnet, D., \& Drewnowski, A. (2006). Higher Satiety Ratings Following Yogurt Consumption Relative to Fruit Drink or Dairy Fruit Drink. Journal of the American Dietetic Association, 106(4), 550-557. https://doi.org/10.1016/j.jada.2006.01.004

Yeomans, M. R., \& Chambers, L. (2011). Satiety-relevant sensory qualities enhance the satiating effects of mixed carbohydrate-protein preloads. American Journal of Clinical Nutrition, 94(6), 1410-1417. https://doi.org/10.3945/ajcn.111.011650 
Table 1 Nutrient content of the samples and nutrient content and portion sizes of portions offered in the satiety test.

\begin{tabular}{|c|c|c|c|c|c|c|c|c|c|c|}
\hline & \multicolumn{5}{|c|}{ Samples (/l00 g) } & \multicolumn{5}{|c|}{ Satiety test portions (/portion) } \\
\hline & $\begin{array}{c}\text { WG } \\
\text { sourdoug } \\
\text { h rye } \\
\text { bread }\end{array}$ & $\begin{array}{c}\text { Extruded } \\
\text { WG rye } \\
\text { flakes }\end{array}$ & $\begin{array}{c}\text { Extruded } \\
\text { WG rye } \\
\text { puffs }\end{array}$ & $\begin{array}{c}\text { Refined } \\
\text { wheat } \\
\text { bread }\end{array}$ & $\begin{array}{l}\text { Black- } \\
\text { currant } \\
\text { juice }\end{array}$ & $\begin{array}{c}\text { WG } \\
\text { sourdough } \\
\text { rye bread } \\
+ \text { juice }\end{array}$ & $\begin{array}{l}\text { Extruded } \\
\text { WG rye } \\
\text { flakes } \\
+ \text { juice }\end{array}$ & $\begin{array}{l}\text { Extruded } \\
\text { WG rye } \\
\text { puffs } \\
+ \text { juice }\end{array}$ & $\begin{array}{l}\text { WG rye } \\
\text { smoothie }\end{array}$ & $\begin{array}{c}\text { Refined } \\
\text { wheat } \\
\text { bread } \\
+ \text { juice }\end{array}$ \\
\hline \multicolumn{11}{|l|}{ Nutrient content } \\
\hline Energy (kcal) & 200 & 322 & 330 & 253 & 38 & 382 & 382 & 382 & 382 & 382 \\
\hline Starch $(g)$ & 35.4 & 57.7 & 59.8 & 46.4 & ns & 33.7 & 34.1 & 34.5 & 34.1 & 34.8 \\
\hline Protein (g) & 6.5 & 9.7 & 9.8 & 9.1 & ns & 6.2 & 5.7 & 5.6 & 5.7 & 6.8 \\
\hline Fat $(\mathrm{g})$ & 0.6 & 1.2 & 1.3 & 2.4 & ns & 0.6 & 0.7 & 0.7 & 0.7 & 1.8 \\
\hline Total dietary fibre $(\mathrm{g})$ & 13.3 & 20.7 & 19.8 & 4.7 & ns & 12.6 & 12.2 & 11.4 & 12.2 & 3.6 \\
\hline Soluble dietary fibre $(\mathrm{g})$ & 7.5 & 9.5 & 10.7 & 2.3 & ns & 7.2 & 5.6 & 6.2 & 5.6 & 1.7 \\
\hline Insoluble dietary fibre $(\mathrm{g})$ & 3.6 & 3.7 & 4.0 & 1.5 & ns & 3.4 & 2.2 & 2.3 & 2.2 & 1.1 \\
\hline Oligosaccharides (g) & 2.2 & 7.6 & 5.2 & 1.0 & ns & 2.0 & 4.5 & 3.0 & 4.5 & 0.7 \\
\hline Sugar (g) & - & - & - & - & 9.6 & 48 & 48 & 48 & 48 & 48 \\
\hline \multicolumn{11}{|l|}{ Portion sizes (g) } \\
\hline Cereal product & & & & & & & 59 & 58 & 58 & 75 \\
\hline Juice & & & & & & 500 & 500 & 500 & 500 & 500 \\
\hline Total & & & & & & 595 & 559 & 558 & 559 & 575 \\
\hline
\end{tabular}


Table 2 Characteristics of the study participants. Values are means $\pm \mathrm{SD}, \mathrm{n}=26$ in the mastication trial and $n=16$ (subset) in satiety trial.

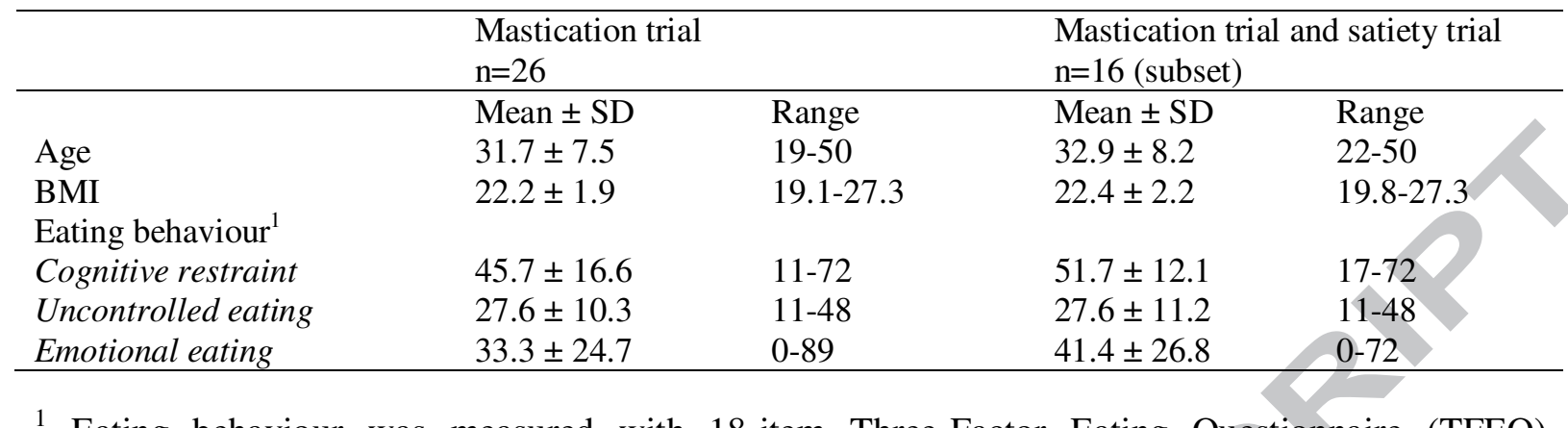

1 Eating behaviour was measured with 18-item Three-Factor Eating Questionnaire (TFEQ)

(Karlsson, Persson, Sjöström, \& Sullivan, 2000) 
Table 3 Moisture contents of the samples and textural properties measured with TPA (breads) and TA (extrudates).

\begin{tabular}{lcccc}
\hline & $\begin{array}{c}\text { WG sourdough rye } \\
\text { bread }\end{array}$ & $\begin{array}{c}\text { Refined wheat } \\
\text { bread }\end{array}$ & $\begin{array}{c}\text { Extruded WG } \\
\text { rye flakes }\end{array}$ & $\begin{array}{c}\text { Extruded WG } \\
\text { rye puffs }\end{array}$ \\
\hline Moisture (\%) & $39.3 \pm 0.1$ & $32.3 \pm 0.4$ & $7.0 \pm 0.0$ & $5.5 \pm 0.0$ \\
Hardness (N) & $24 \pm 8$ & $4 \pm 1$ & $1530 \pm 390$ & $27 \pm 3$ \\
Cohesiveness & $0.4 \pm 0.1$ & $0.7 \pm 0.0$ & - & - \\
Chewiness & $5.1 \pm 1.8$ & $2.0 \pm 0.5$ & - & - \\
Adhesiveness & $-0.010 \pm 0.014$ & $-0.133 \pm 0.332$ & - & $0.6 \pm 0.1$ \\
& & & $98.3 \pm 37.3$ & $21 \pm 5$ \\
Crispiness work & & & $0.004 \pm 0.002$ & \\
Crispiness index $\left(\mathrm{x}^{10-3}\right)$ & & & & \\
\end{tabular}


Table 4 Oral processing parameters. Values are means $\pm S D, n=26$. Different superscript letters in a row indicate statistically significant difference $(\mathrm{p}<0.05)$ between products. Extrapolated parameters represent oral processing parameters for the portion size served in the satiety trial.

\begin{tabular}{|c|c|c|c|c|c|c|c|}
\hline & $\begin{array}{l}\text { WG sourdough } \\
\text { rye bread }\end{array}$ & $\begin{array}{l}\text { Extruded WG } \\
\text { rye flakes }\end{array}$ & $\begin{array}{l}\text { Extruded WG } \\
\text { rye puffs }\end{array}$ & $\begin{array}{l}\text { WG rye } \\
\text { smoothie }\end{array}$ & $\begin{array}{c}\text { Refined wheat } \\
\text { bread }\end{array}$ & $\chi^{2}$ & Sig. \\
\hline \multicolumn{8}{|l|}{$\begin{array}{l}\text { Parameters for } \\
\text { mouthful of food }\end{array}$} \\
\hline Number of chews & $27 \pm 10^{b}$ & $28 \pm 7^{b}$ & $11 \pm 5^{\mathrm{a}}$ & $7 \pm 4^{\mathrm{a}}$ & $20 \pm 8^{b}$ & 85.8 & $<0.001$ \\
\hline $\begin{array}{l}\text { Total oral processing } \\
\text { time }(\mathrm{s})\end{array}$ & $20 \pm 9^{c}$ & $21 \pm 8^{\mathrm{c}}$ & $8 \pm 4^{\mathrm{a}}$ & $4 \pm 3^{a}$ & & 84.9 & $<0.001$ \\
\hline $\begin{array}{l}\text { Time of EMG } \\
\text { activity (s) }\end{array}$ & $9 \pm 3^{\mathrm{bc}}$ & $10 \pm 3^{\mathrm{c}}$ & $4 \pm 2^{\mathrm{a}}$ & $2 \pm 1^{\mathrm{a}}$ & $3^{\mathrm{b}}$ & 85.6 & $<0.001$ \\
\hline Duty cycle $(\%)^{1}$ & $46 \pm 3^{\mathrm{a}}$ & $48 \pm 4^{\mathrm{a}}$ & $53 \pm 6^{\mathrm{b}}$ & $61 \pm 13^{\mathrm{b}}$ & $48 \pm 3^{\mathrm{a}}$ & 46.6 & $<0.001$ \\
\hline Relative force $(\%)^{2}$ & $90 \pm 15^{\mathrm{b}}$ & $101 \pm 25^{\mathrm{b}}$ & $75 \pm 23^{\mathrm{ab}}$ & $45 \pm 23^{\mathrm{a}}$ & $80 \pm 17^{b}$ & 60.0 & $<0.001$ \\
\hline Relative work ${ }^{3}$ & $8 \pm 3^{\mathrm{bc}}$ & $11 \pm 3^{\mathrm{c}}$ & $3 \pm$ & $1 \pm 1^{\mathrm{a}}$ & $5 \pm 2^{\mathrm{b}}$ & 80.7 & $<0.001$ \\
\hline \multicolumn{8}{|l|}{$\begin{array}{l}\text { Extrapolated } \\
\text { parameters for food } \\
\text { portion }\end{array}$} \\
\hline Number of chews & $340 \pm 130^{\mathrm{a}}$ & $480 \pm 120^{b}$ & $640 \pm 260^{b}$ & $210 \pm 130^{\mathrm{a}}$ & $380 \pm 160^{b}$ & 80.3 & $<0.001$ \\
\hline $\begin{array}{l}\text { Total oral processing } \\
\text { time }(\mathrm{s})\end{array}$ & $250 \pm 110^{\mathrm{ab}}$ & $360 \pm 130^{c}$ & $440 \pm 210^{c}$ & $140 \pm 100^{\mathrm{a}}$ & $280 \pm 110^{b}$ & 73.7 & $<0.001$ \\
\hline $\begin{array}{l}\text { Time of EMG } \\
\text { activity (s) }\end{array}$ & $110 \pm 40^{\mathrm{ab}}$ & $70 \pm 50^{c}$ & $220 \pm 90^{c}$ & $70 \pm 40^{\mathrm{a}}$ & $130 \pm 50^{\mathrm{b}}$ & 82.2 & $<0.001$ \\
\hline Relative work ${ }^{3}$ & $100 \pm 30^{b}$ & $190 \pm 50^{c}$ & $160 \pm 70^{c}$ & $40 \pm 40^{\mathrm{a}}$ & $100 \pm 40^{\mathrm{b}}$ & 70.2 & $<0.001$ \\
\hline
\end{tabular}

${ }^{1}$ Time of EMG activity/Total oral processing time

${ }^{2}$ Chewing force of the product related to chewing force of chewing gum

${ }^{3}$ Time of EMG activity $\mathrm{x}$ relative force 


\section{FIGURE CAPTIONS}

Figure 1 Photographs of the food samples. Rye smoothie was prepared mixing grinded wholegrain rye flakes with blackcurrant juice and letting the mixture stand for 15 minutes

Figure $2 \mathrm{~A}$ : EMG data after $50 \mathrm{~Hz}$ notch filtering for a single participant, chewing gum sample. The three mastication sequences are each labeled with 'start' and 'stop'. B: Further analysis of the second mastication sequence of the data above. EMG power was computed, highpass-filtered, squared (blue curve) and smoothed (red curve), after which chews were detected (black block curve). The event data were used for number of chews, total oral processing time, time of EMG activity and duty cycle. The smoothed EMG power was used for relative force and, when multiplied by time of EMG activity, the relative work.

Figure 3 Perceived characteristics of the samples evaluated by the trained sensory panel $(n=2 \times 12)$. Sensory intensities were evaluated on an intensity scale 0-10. Values are means. There were statistically significant differences $(\mathrm{p}<0.001)$ between the samples in each attribute.

Figure 4 A) Expected satiety before and after mastication $(n=26)$ and B) pleasantness of the portions after eating the portion $(n=16)$. Expected satiety was evaluated based on photograph representing study portions together with mastication trial. Pleasantness of each study portion was evaluated together with satiety trial right after consuming the portion. The evaluations were done on a VAS scale 0-10. Values are means \pm SD. Different letters above bars indicate statistically significant difference between evaluations (in 2A uppercase letters for values before mastication and lowercase letters for values after mastication). Asterixes in $2 \mathrm{~A}$ indicate significant difference within product before and after mastication trial $* * \mathrm{p}<0.01, * * * \mathrm{p}<0.001$.

Figure 5 Changes VAS ratings for A) hunger, B) fullness, C) desire to eat, D) prospective food consumption, E) satiety and F) average appetite score during 210 min postprandial period in healthy women for wholegrain rye bread (----), wholegrain rye smoothie $(\cdots \downarrow \cdots)$, wholegrain rye puffs (-$\mathrm{x}--)$, wholegrain rye flakes (-- $\mathbf{\Delta}--)$ and refined wheat bread (-- ---$)$. Values are means with their standard errors represented by vertical bars, $n=16$. Significant product effect was found for hunger, fullness, desire to eat, prospective food consumption and average appetite score. The time points with statistically significant differences $(\mathrm{p}<0.05)$ between products are marked with asterix $(*)$. 


\section{Rye bread}

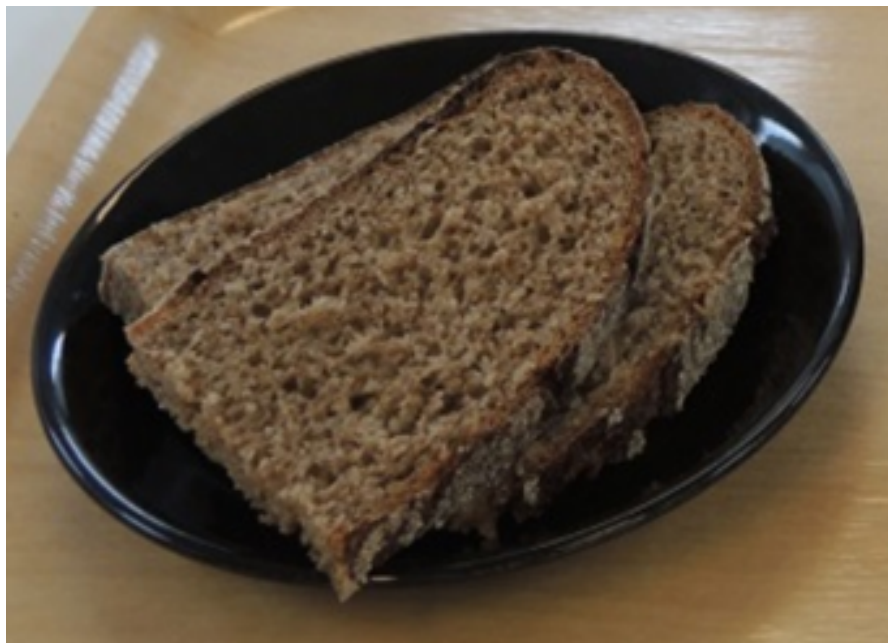

Rye puffs

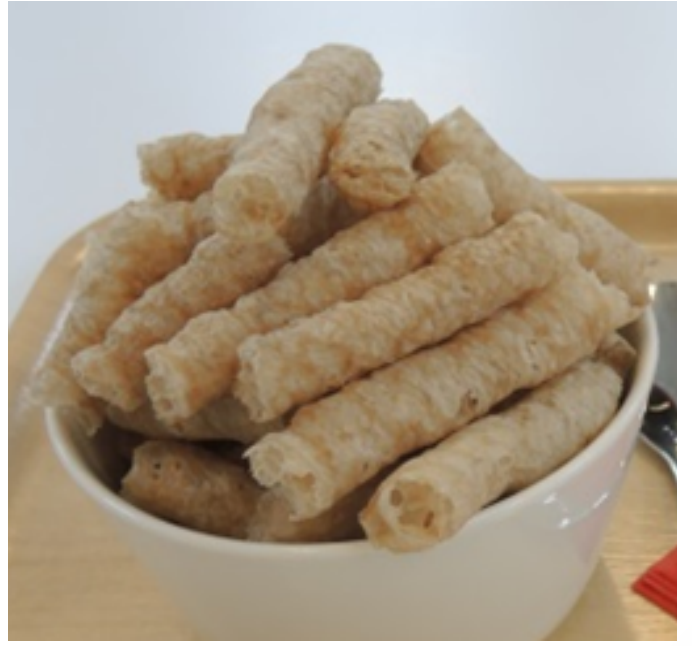

\section{Rye flakes}

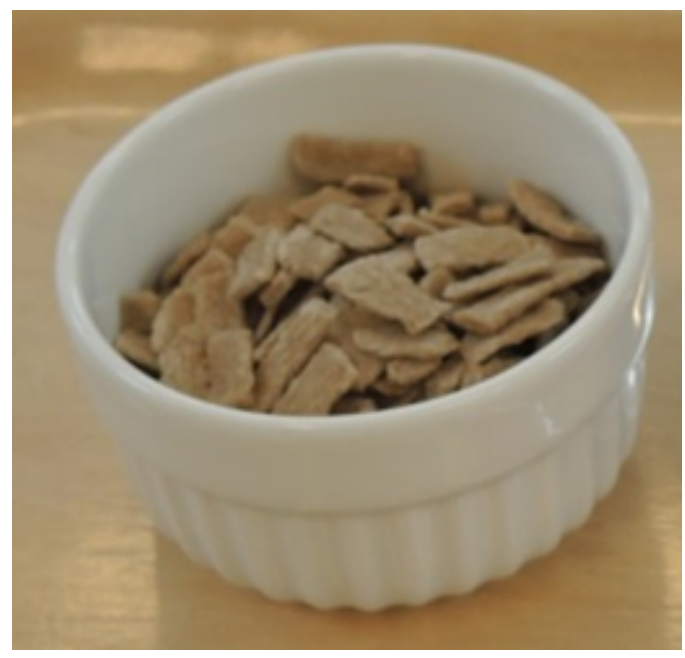

Grinded rye flakes Blackcurrant juice
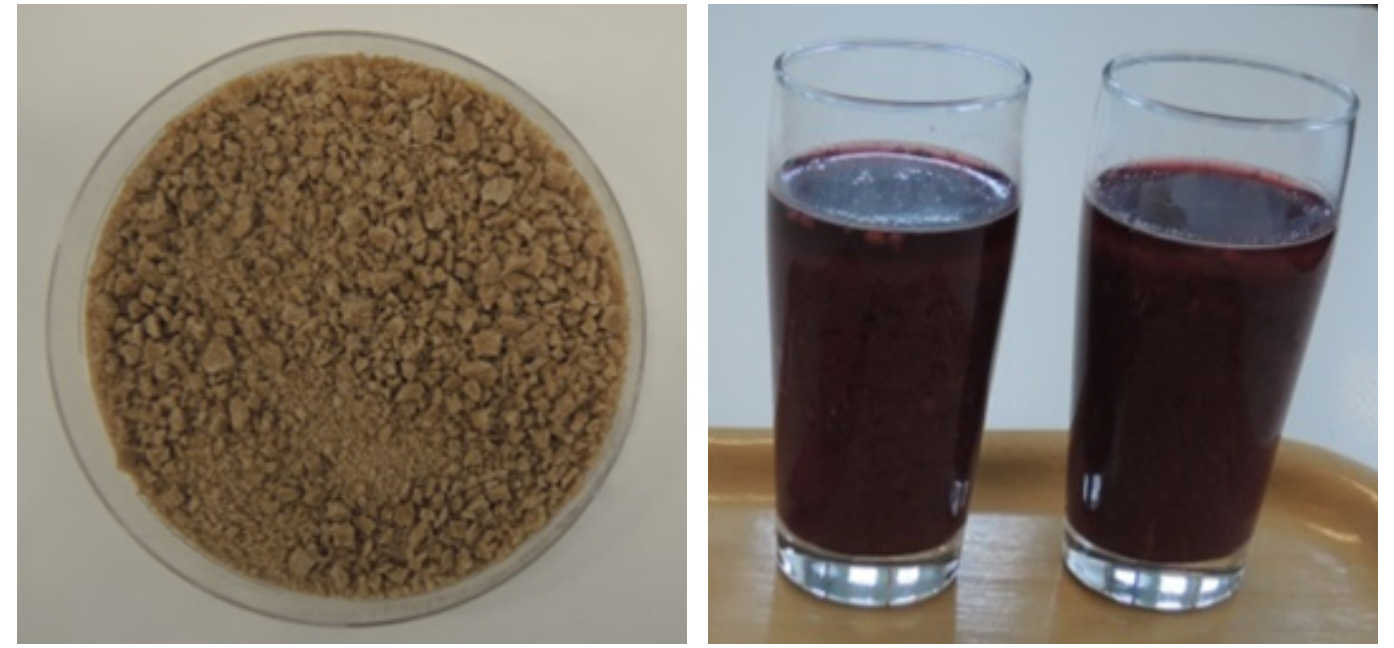


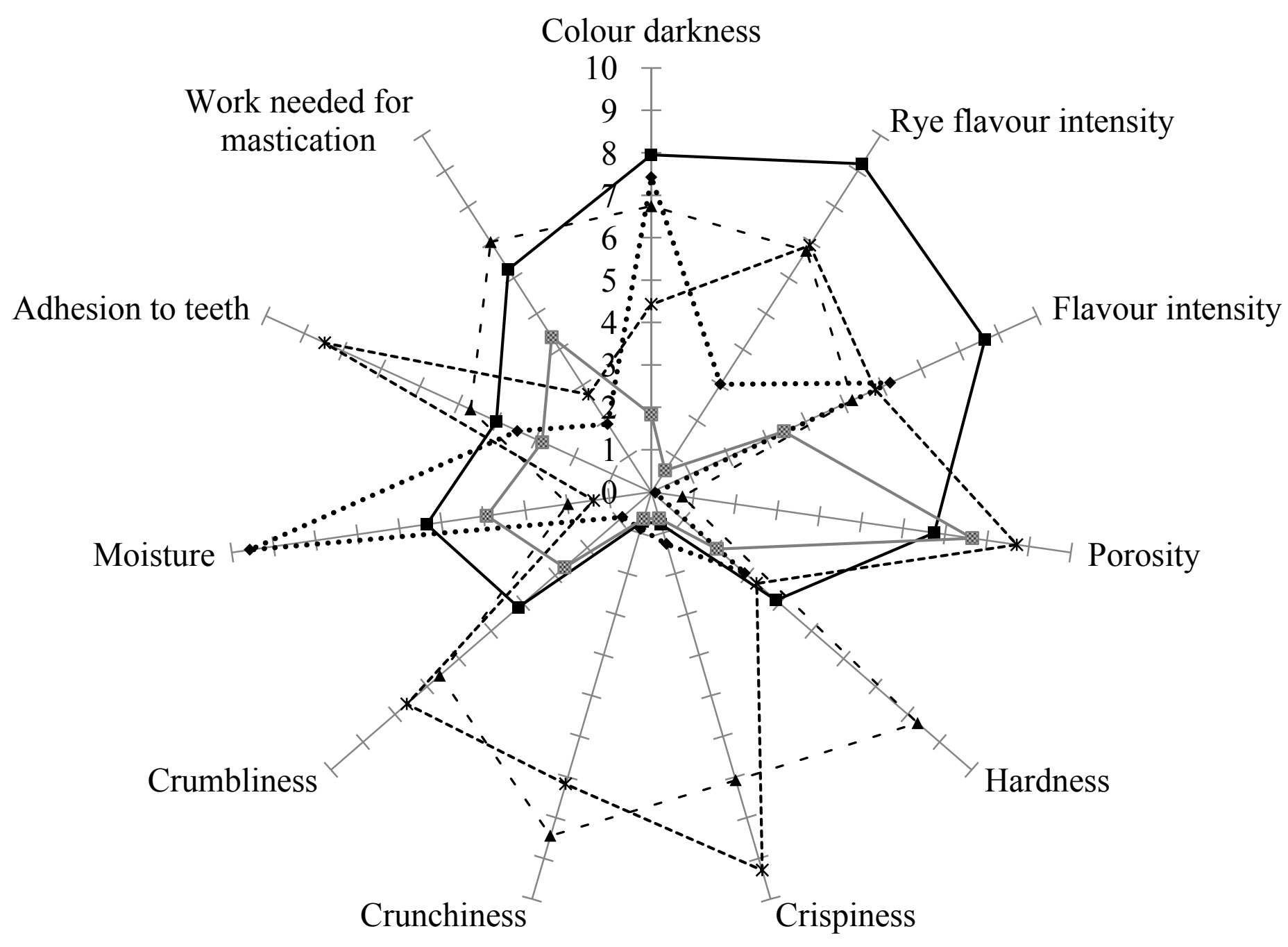

$\rightarrow$ Rye bread

- $\_$- Rye flakes

--*--Rye puffs

..... Rye smoothie

- - Wheat bread 
A) Expected satiety before and after mastication

B) Pleasantness

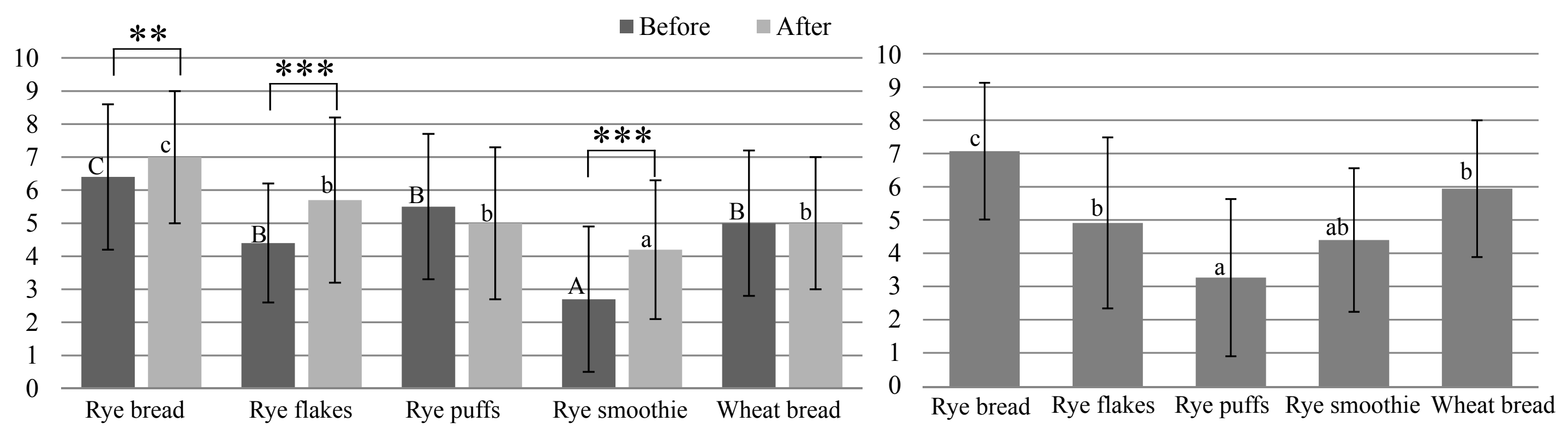


A

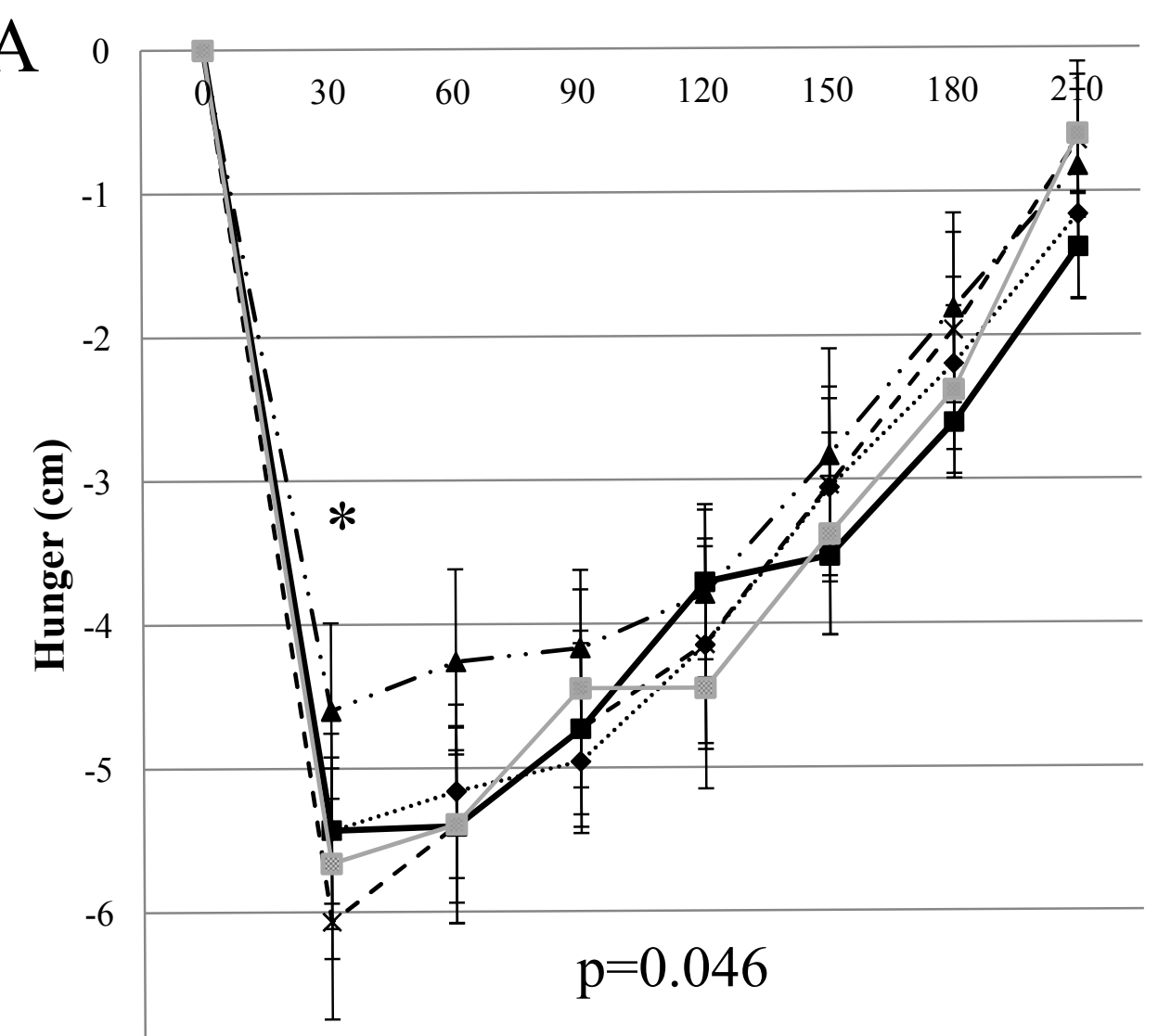

C

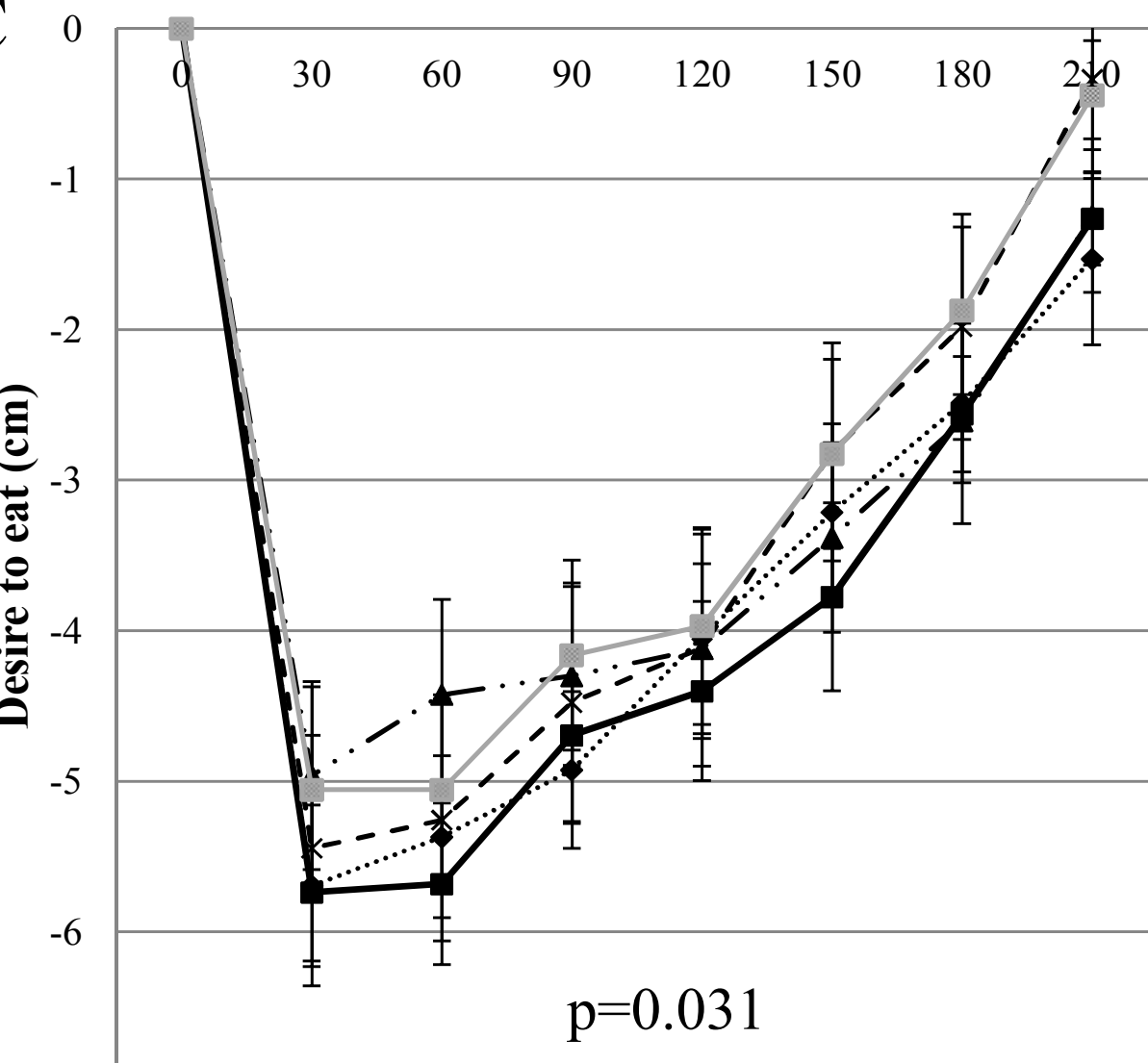

E

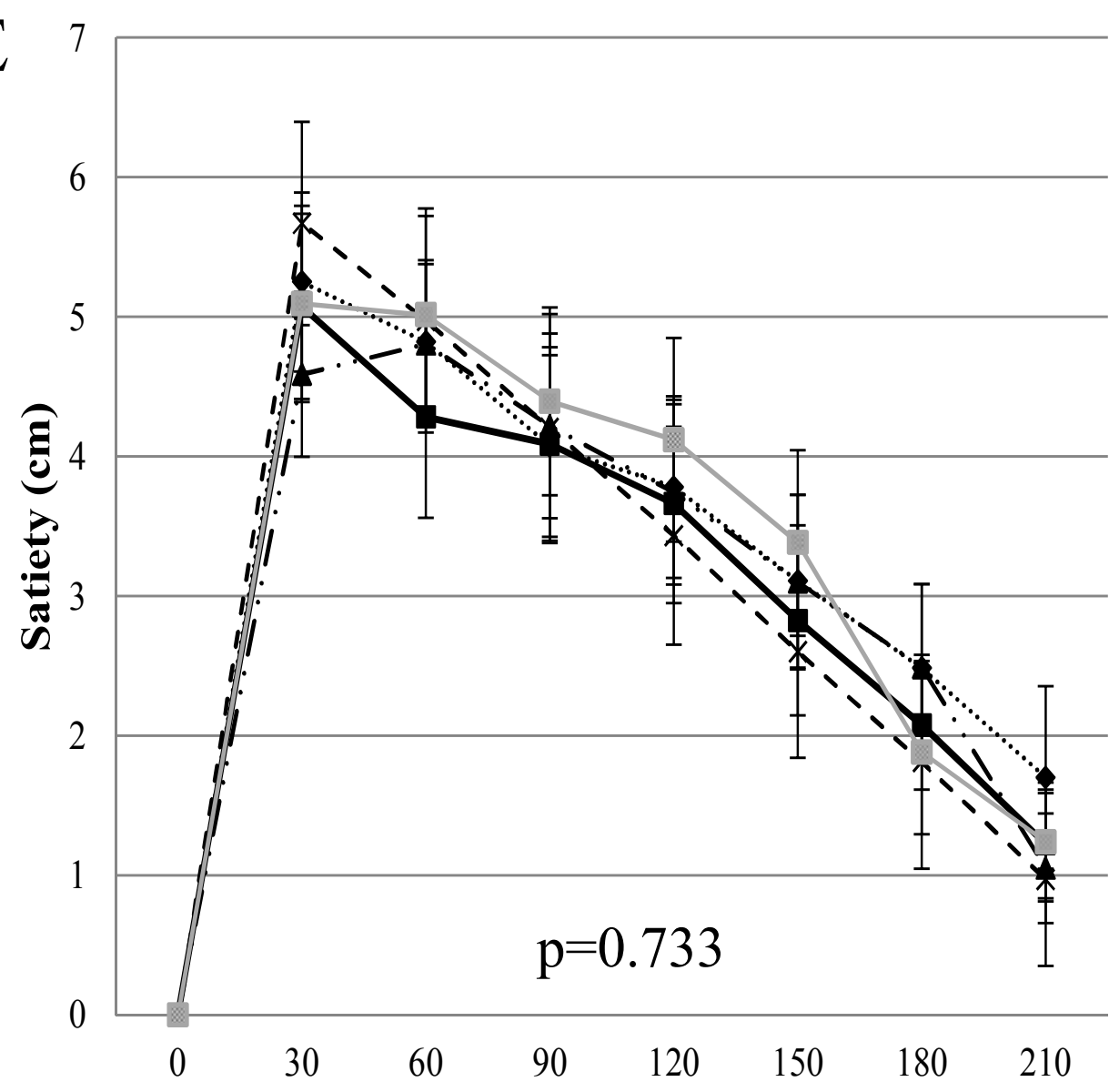

B 7
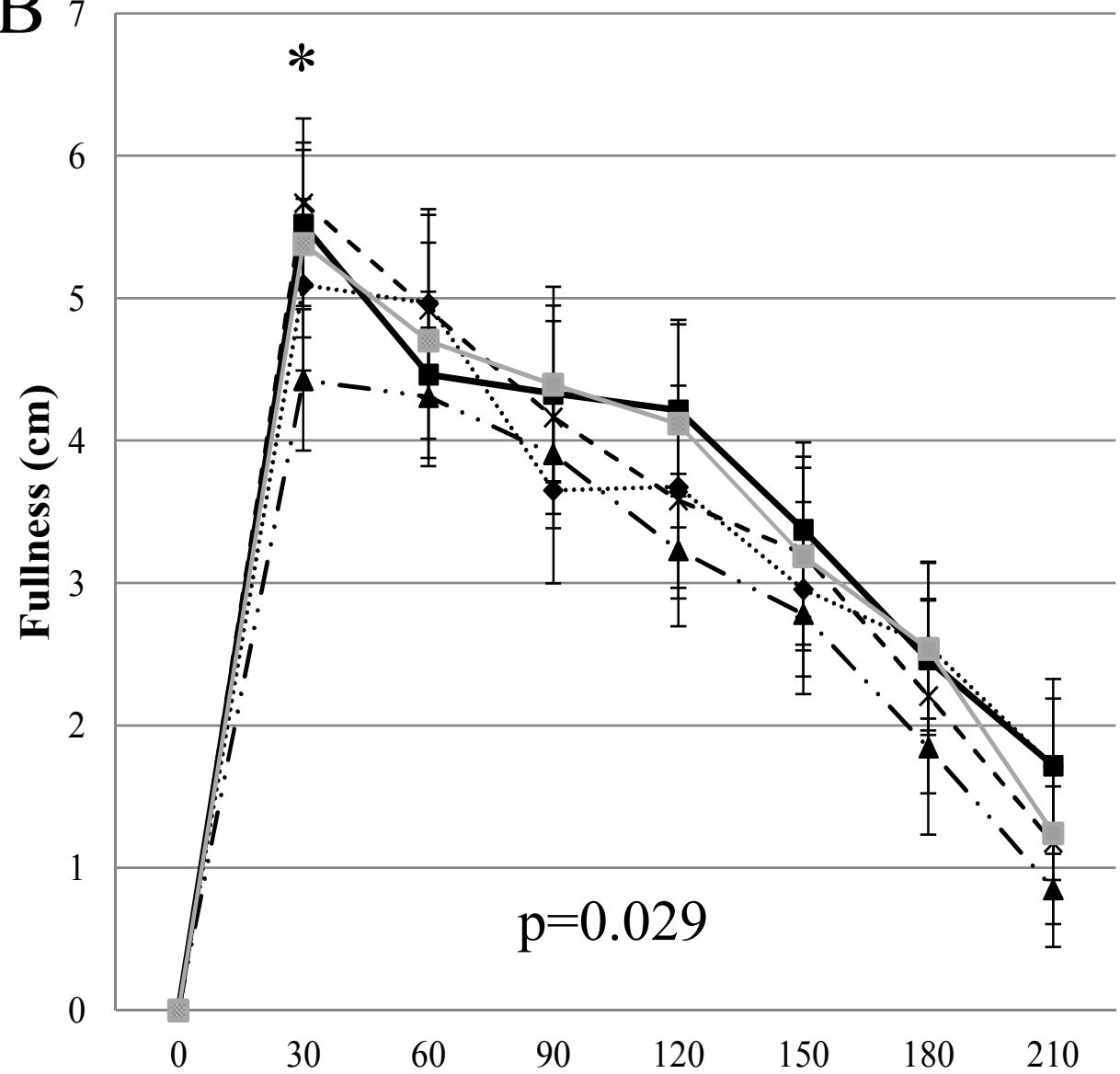

D 0

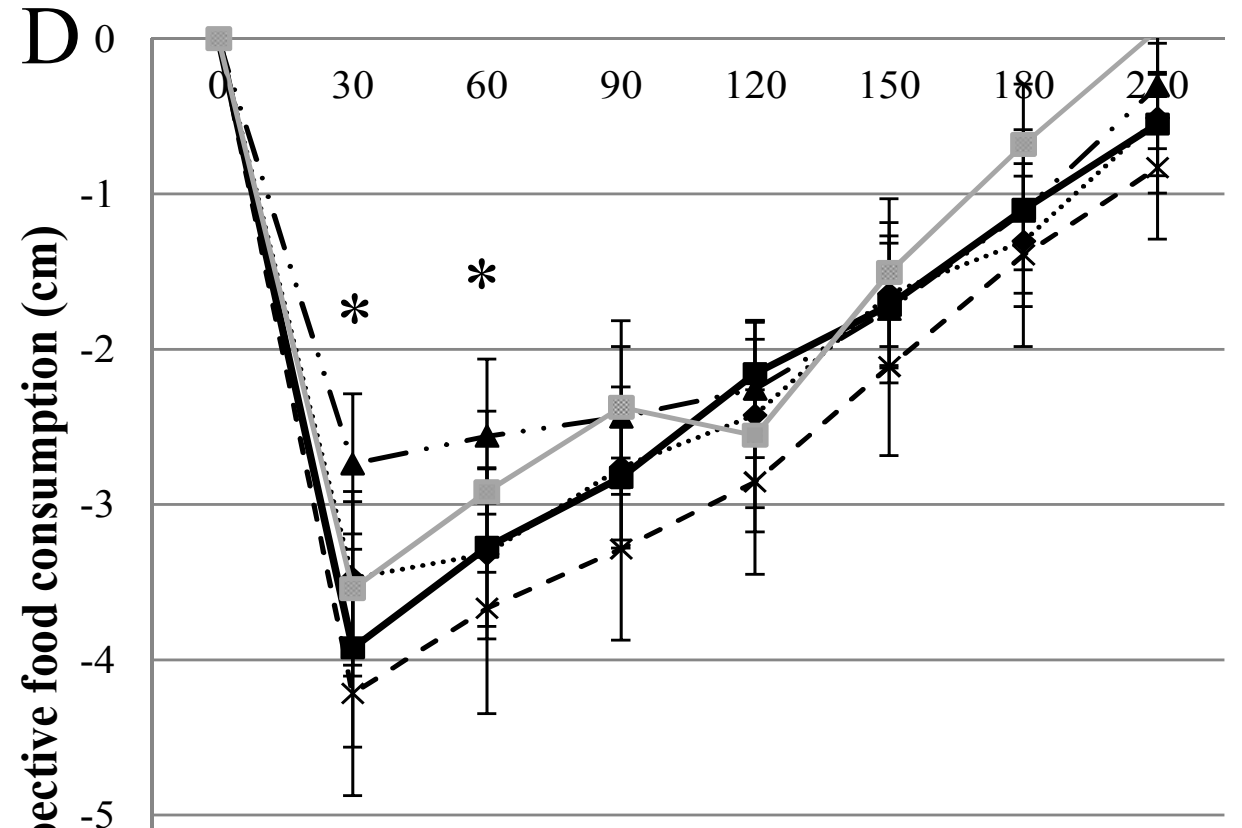

$\mathrm{p}=0.002$

F 0

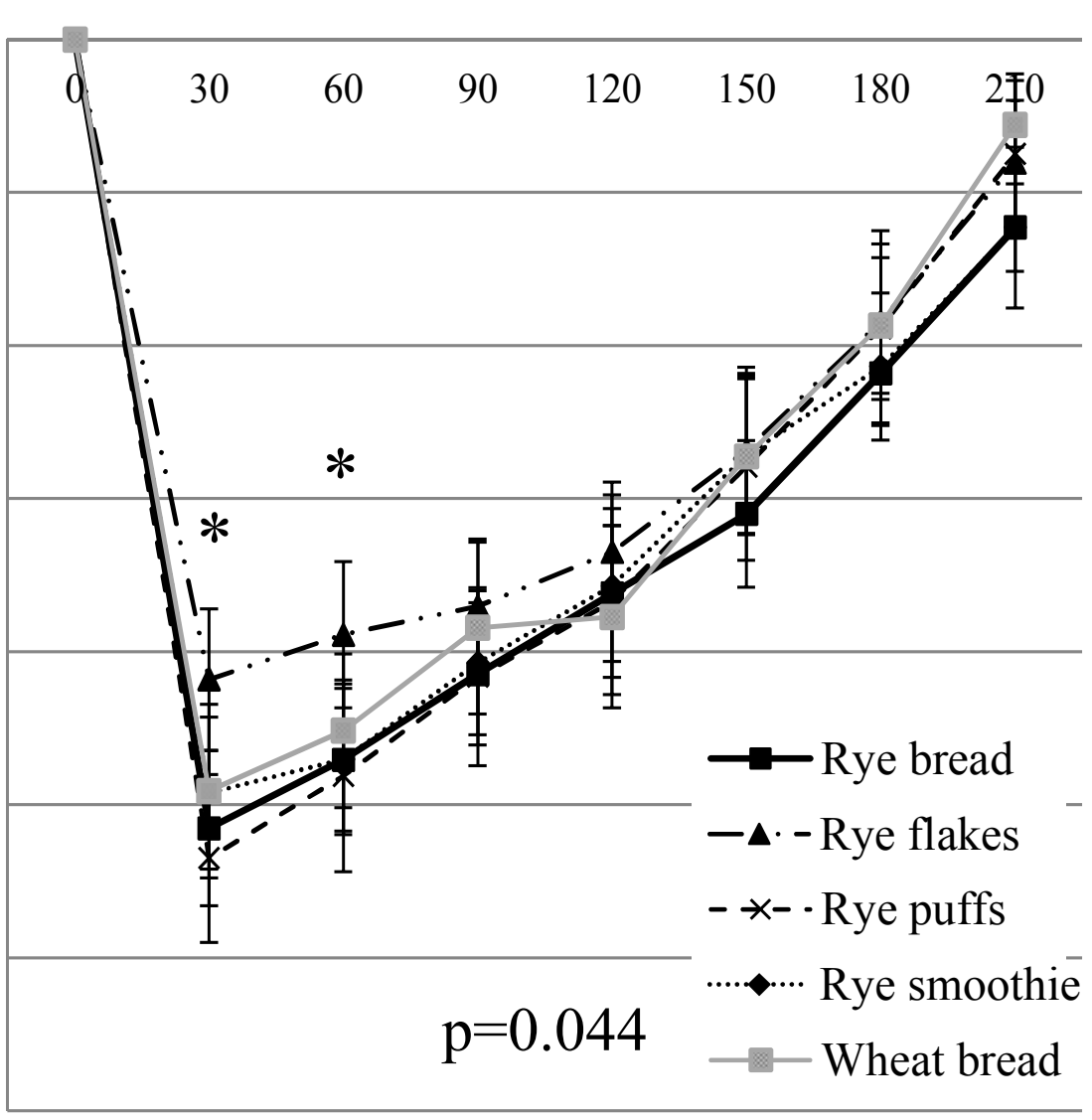




\section{Highlights:}

- Food structure influences satiety in the early post-prandial period

- There is a link between mastication effort and satiety

- Evaluated pleasantness modulate satiety response 